\title{
Early hypertension is associated with better clinical outcomes in gastric cancer patients treated with ramucirumab plus paclitaxel
}

\author{
Naoki Fukuda ${ }^{1}$, Daisuke Takahari $^{1}$, Takeru Wakatsuki ${ }^{1}$, Hiroki Osumi ${ }^{1}$, Izuma \\ Nakayama ${ }^{1}$, Tomohiro Matsushima ${ }^{1}$, Takashi Ichimura ${ }^{1}$, Mariko Ogura ${ }^{1}$, Masato \\ Ozaka', Mitsukuni Suenaga ${ }^{1}$, Eiji Shinozaki ${ }^{1}$, Keisho Chin ${ }^{1}$ and Kensei Yamaguchi ${ }^{1}$ \\ ${ }^{1}$ Department of Gastroenterology, The Cancer Institute Hospital of JFCR, Tokyo, Japan \\ Correspondence to: Daisuke Takahari, email: daisuke.takahari@jfcr.or.jp \\ Keywords: ramucirumab; gastric cancer; hypertension; paclitaxel; toxicity \\ Received: December 04, 2017 Accepted: February 25, 2018 Epub: March 08, 2018 Published: March 16, 2018 \\ Copyright: Fukuda et al. This is an open-access article distributed under the terms of the Creative Commons Attribution License \\ 3.0 (CC BY 3.0), which permits unrestricted use, distribution, and reproduction in any medium, provided the original author and \\ source are credited.
}

\section{ABSTRACT}

Anti-vascular endothelial growth factor (VEGF) therapeutics such as bevacizumab, which are widely used in cancer treatment, commonly leads to hypertension. Moreover, bevacizumab-induced hypertension is associated with improved clinical outcomes in several cancers. We retrospectively analyzed 89 patients with histologically confirmed advanced gastric cancer who received the human monoclonal anti-VEGF receptor-2 antibody ramucirumab plus paclitaxel at our hospital between June 2015 and October 2016 to evaluate the impact of treatment-associated hypertension occurring within the first two treatment cycles ("early hypertension") on outcome. The objective response rate was $\mathbf{4 0} \%$, median progression-free survival was $\mathbf{5 . 4}$ months, and overall survival was $\mathbf{1 0 . 4}$ months, which is similar to previous reports. Early hypertension in patients who received more than two cycles of ramucirumab + paclitaxel was associated with longer progression-free and overall survival. Objective response rates were also higher in patients with early hypertension. These data indicate that early hypertension may be predictive of better outcomes in gastric cancer patients who receive ramucirumab + paclitaxel treatment.

\section{INTRODUCTION}

According to a recent survey by the National Cancer Center of Japan, gastric cancer is the second most commonly diagnosed malignant cancer and the third leading cause of cancer-related death in Japan [1]. For patients with recurrent, metastatic, or advanced gastric cancer, fluoropyrimidine + platinum-based chemotherapy prolonged survival and improved quality of life (QOL) in several clinical trials [2-5]. However, although the impact of second-line or salvage chemotherapy in gastric cancer patients has long been limited, taxanes and irinotecan are commonly used in East Asia [6].

Ramucirumab is a novel human IgG-1 monoclonal antibody against the extracellular domain of vascular endothelial growth factor receptor-2 (VEGFR-2). Ramucirumab prevents VEGF ligands, including
VEGF-A, VEGF-C, and VEGF-D, from binding to VEGFR-2, thus inhibiting the VEGF signaling pathway [7]. In the RAINBOW trial, second-line treatment with ramucirumab in combination with paclitaxel prolonged overall survival (OS) and progression-free survival (PFS) compared to paclitaxel alone [8]. In the REGARD trial, second-line ramucirumab monotherapy improved OS and PFS compared to the placebo [9]. Ramucirumab has therefore been approved as a second-line or later treatment for advanced gastric cancer in the U.S., Europe, and Japan.

Biomarkers that predict the efficacy of ramucirumab for the treatment of gastric cancer have not yet been identified. Hypertension is a common adverse event associated with anti-VEGF therapies such as bevacizumab or ramucirumab [10]. In the RAINBOW and the REGARD trials, approximately $20 \%$ of patients experienced hypertension of any grade during ramucirumab treatment 
$[8,9]$. The occurrence of hypertension during treatment with anti-VEGF agents is associated with better outcomes in various cancers.

Scartozzi et al. reported that patients with metastatic colorectal cancer who experienced bevacizumab-induced hypertension had a better response rate ( $75 \%$ vs. $32 \%$ ) and longer median PFS (14.5 months vs. 3.1 months) [11]. Rixe et al. reported that the response rate was higher in metastatic renal cell carcinoma patients who developed hypertension during treatment with sunitinib than in those who did not $(p=0.009)$ [12]. Dahlberg et al. also found that the onset of hypertension during bevacizumab treatment was associated with improved OS and PFS [13].

To the best of our knowledge, the relationship between ramucirumab-induced hypertension and the treatment efficacy of ramucirumab in gastric cancer patients has not yet been examined. Here, we conducted a retrospective analysis to determine whether treatment outcomes were associated with treatment-related hypertension in advanced gastric cancer patients treated with ramucirumab + paclitaxel.

\section{RESULTS}

\section{Patients}

Between June 2015 and October 2016, 89 patients were treated with ramucirumab + paclitaxel in our department. The clinical characteristics of these patients are shown in Table 1 . The median age was 67 years (range $35-83$ years) and $53 \%$ of the patients were male. The ECOG (Eastern Cooperative Oncology Group) performance status (PS) was $\geq 2$ in $10(11 \%)$ patients. Thirty-two (36\%) patients displayed the intestinal histological subtype and 55 (62\%) displayed the diffuse subtype; the remaining two patients displayed 'other' and 'unknown' subtypes. Twenty-one (24\%) patients were HER2-positive. Ramucirumab + paclitaxel was administered as a second-line chemotherapy in $79(89 \%)$ patients, and 55 patients (62\%) had previously undergone surgery to remove the primary tumor. The time until disease progression following first-line therapy was $\geq 6$ months in $22(25 \%)$ patients; nine (10\%) patients experienced disease progression during adjuvant therapy. Forty (45\%) patients had measurable disease, and 26 (34\%) patients had more than two metastatic sites. Eleven patients $(12 \%)$ had a previous history of hypertension and had received medication to treat it.

\section{Exposure to chemotherapy}

The median number of treatment courses was five (range 1-21). Dose reductions or delays of paclitaxel treatment were observed in $57(64 \%)$ patients, and discontinuation of paclitaxel was observed in eight
(9\%) patients. After ramucirumab failure, additional chemotherapy, including irinotecan, platinum-containing regimens, or other drugs undergoing clinical trials, was administered in 23 patients, which comprised $36 \%$ of the patients who experienced disease progression.

\section{Efficacy}

As of the data collection cutoff of January 24, 2017, the median follow-up time for all enrolled patients was 7.1 months (range $0.5-18.6)$. Seventy-three (82\%) patients experienced PFS events, and 49 (55\%) died. The median PFS was 5.4 months (95\% confidence interval [CI] $4.1-$ $5.9)$, and the median OS was 10.4 months $(95 \% \mathrm{CI} 8.3-$ 13.3) (Figure 1).

Among the patients with measurable disease $(n=40)$, $16(40 \%)$ patients showed a partial response (PR), nine (23\%) patients had stable disease (SD), and 13 (33\%) patients had progressive disease (PD). The objective response rate and disease control rate were $40 \%(95 \% \mathrm{CI}$ $32.2-47.8)$ and $63 \%(95 \% \mathrm{CI} 54.8-70.2)$, respectively (Table 2).

\section{Safety}

The toxicities observed during treatment are listed in Table 3. The most common adverse events were neutropenia (70\%), peripheral neuropathy (46\%), hypertension (38\%), and fatigue (33\%). Other ramucirumab-related toxicities, such as bleeding or hemorrhage $(29 \%)$ and proteinuria $(17 \%)$, were also observed. Treatment was discontinued due to severe toxicity, including liver abscess, cerebral infarction, duodenal perforation, interstitial pneumonia, and aspiration pneumonia, in five $(6 \%)$ patients,. No treatmentrelated deaths occurred.

Among the 33 patients who developed hypertension during treatment, the median onset of hypertension was 33 days (range $4-103$ days, 95\% CI 30.1-44.8). Hypertension grades were determined according to the CTCAE (Common Terminology Criteria for Adverse Events); 27 patients had grade 1-2 hypertension, and six had grade 3 hypertension. For the patients who were taking medication for hypertension upon enrollment into the study, the onset of hypertension was defined as the day when the CTCAE grade became higher than it was at baseline. Twenty-nine (88\%) patients developed hypertension within two treatment cycles. Among the 11 patients who had hypertension upon enrollment, 6 patients progressed to poorly-controlled hypertension. Among these 6 patients, 5 developed early hypertension, although baseline hypertension was not associated with the incidence of early hypertension (odds ratio [OR] 1.86, $p=0.33$ ). Hypertension was successfully controlled in all patients with oral angiotensin II receptor blockers, calcium channel blockers, or both. 
Table 1: Characteristics of the patients with histologically confirmed advanced gastric cancer

\begin{tabular}{|c|c|}
\hline & $\mathrm{n}=\mathbf{8 9}$ \\
\hline Age, yrs; median (range) & $67(35-83)$ \\
\hline$<65 \mathrm{yrs}$ & $39(44 \%)$ \\
\hline$\geq 65 \mathrm{yrs}$ & $50(56 \%)$ \\
\hline \multicolumn{2}{|l|}{ Sex } \\
\hline Male & $47(53 \%)$ \\
\hline Female & $42(47 \%)$ \\
\hline \multicolumn{2}{|l|}{ ECOG performance status: } \\
\hline $0-1$ & $79(89 \%)$ \\
\hline$\geq 2$ & $10(11 \%)$ \\
\hline \multicolumn{2}{|l|}{ Location of primary tumor: } \\
\hline Gastric & $81(91 \%)$ \\
\hline Gastro-esophageal junction & $5(6 \%)$ \\
\hline Remnant gastric & $2(2 \%)$ \\
\hline Unknown & $1(1 \%)$ \\
\hline \multicolumn{2}{|l|}{ Histological subtype: } \\
\hline Intestinal & $32(36 \%)$ \\
\hline Diffuse & $55(62 \%)$ \\
\hline Other & $1(1 \%)$ \\
\hline Unknown & $1(1 \%)$ \\
\hline \multicolumn{2}{|l|}{ HER2 status: } \\
\hline Positive & $21(24 \%)$ \\
\hline Negative & $68(76 \%)$ \\
\hline \multicolumn{2}{|l|}{ No. of metastatic sites: } \\
\hline 1 & $58(65 \%)$ \\
\hline$\geq 2$ & $31(35 \%)$ \\
\hline \multicolumn{2}{|l|}{ Presence of ascites: } \\
\hline Yes & $23(26 \%)$ \\
\hline No & $66(74 \%)$ \\
\hline Peritoneal metastases & $50(56 \%)$ \\
\hline Liver metastases & $22(25 \%)$ \\
\hline Measurable disease & $40(45 \%)$ \\
\hline \multicolumn{2}{|l|}{ No. of prior regimens: } \\
\hline 0 & $1(1 \%)$ \\
\hline 1 & $79(89 \%)$ \\
\hline$\geq 2$ & $9(10 \%)$ \\
\hline Recurrence during adjuvant chemotherapy & $9(10 \%)$ \\
\hline \multicolumn{2}{|c|}{ Time to disease progression after 1st-line therapy: } \\
\hline$\geq 6$ months & $67(75 \%)$ \\
\hline$<6$ months & $20(22 \%)$ \\
\hline Unknown & $2(2 \%)$ \\
\hline \multicolumn{2}{|l|}{ Previous surgery for gastric cancer: } \\
\hline Yes & $55(62 \%)$ \\
\hline Total gastrectomy & $24(27 \%)$ \\
\hline Partial gastrectomy & $30(34 \%)$ \\
\hline Other & $1(1 \%)$ \\
\hline Previous history of hypertension & $11(12 \%)$ \\
\hline
\end{tabular}

*ECOG: Eastern Cooperative Oncology Group. 


\section{The association between outcomes and hypertension}

Based on a previous report, we defined any grade of hypertension observed within two treatment cycles as 'early hypertension;' early hypertension was considered a candidate predictive factor to eliminate the any bias associated with the duration of treatment [14].

In the univariate analysis with the Kaplan-Meier method, hypertension within two treatment cycles was associated with longer PFS (6.7 vs. 3.8 months, $p<0.001$ ) and OS (15.0 vs. 7.3 months, $p<0.01$ ) (Figure 2a, 2b). Similar results were observed in patients who received more than two cycles of ramucirumab + paclitaxel (PFS; 6.7 vs. 4.4 months, $p<0.01$. OS; 15.0 vs. 10.1 months, $p=0.01$ ) (Figure 2c, 2d). Fisher's exact test revealed that patients who developed early hypertension had a higher objective response rate $(63 \%$ vs. $25 \%, p<0.03)$. The multivariate analysis was performed using the Cox hazard regression model and was adjusted for age ( $<65 \mathrm{vs} . \geq 65$ yrs), sex (male vs. female), ECOG performance status (2 vs. $0-1)$, number of prior regimens ( $\geq 2$ vs. $0-1)$, number of metastatic sites ( $\geq 2$ vs. $0-1$ ), and presence of primary tumor. In that analysis, early hypertension was associated with longer PFS (hazard ratio [HR] 0.39, 95\%CI $0.21-$ $0.73, \mathrm{p}<0.01$ ) and longer OS (HR 0.45, 95\%CI 0.21-0.96, $\mathrm{p}<0.05)$ in patients who received more than two cycles of ramucirumab + paclitaxel (Table 4$)$.

\section{DISCUSSION}

In our analysis, ramucirumab + paclitaxel treatment was associated with high efficacy and tolerability, which

(a)

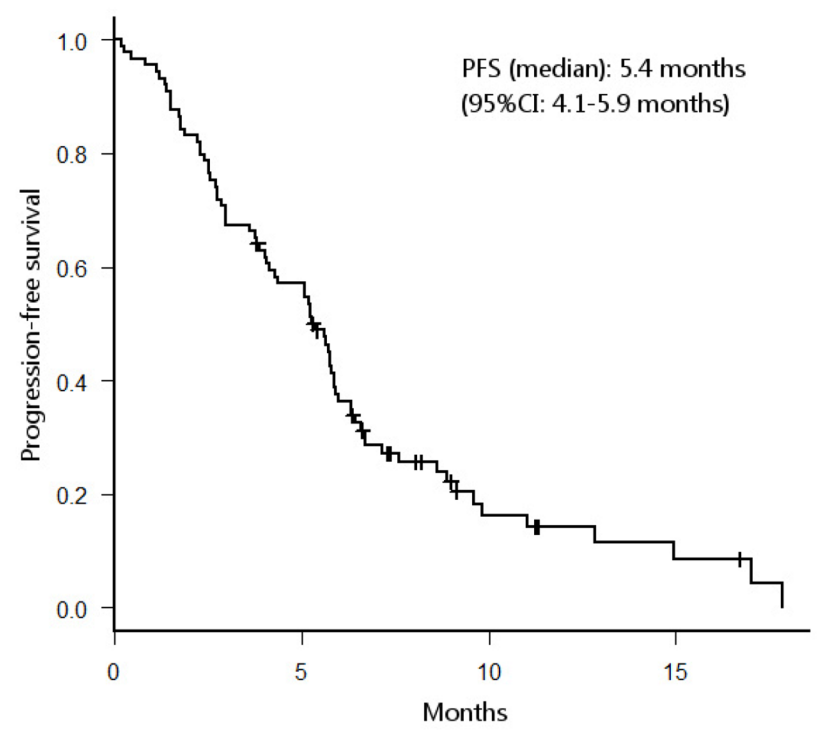

was similar to findings reported in the RAINBOW trial [8]. Moreover, we found that the efficacy of ramucirumab + paclitaxel treatment was associated with treatmentrelated hypertension.

Although hypertension is a common toxicity associated with anti-VEGF therapy, the mechanisms underlying VEGF inhibitor-induced hypertension remain unknown. Because VEGFR-2 signaling activates endothelial nitric oxide synthase (eNOS) and increases nitric oxide (NO) production through the PI3K/Akt signaling pathway, anti-VEGF therapy may decrease NO levels, leading to vasoconstriction and increased blood pressure [15]. VEGF signaling also plays a role in the maintenance of capillary networks; inhibition of this signaling causes endothelial dysfunction and capillary rarefaction, which in turn increases blood pressure [16]. Although these two studies focused mainly on bevacizumab, the findings might also apply to ramucirumab as both drugs inhibit VEGF-A signaling.

Associations between bevacizumab-induced hypertension and treatment outcomes have been reported [11-13]. Although several authors reported a relationship similar to that observed in this study, in which hypertension during treatment was associated with increased efficacy of ramucirumab, this association remains controversial. In the ROSE/TRIO-012 trial for breast cancer, treatmentemergent hypertension of any grade that occurred during the first two ramucirumab + docetaxel treatment cycles was associated with longer OS (HR 0.73, 95\%CI 0.534$0.999)$ in the exploratory analysis $[14,17]$. In a study of treatment for hepatocellular carcinoma, a trend towards longer OS was also observed in patients who developed hypertension during ramucirumab treatment (23.1 vs. 6.1 months) [18].

(b)

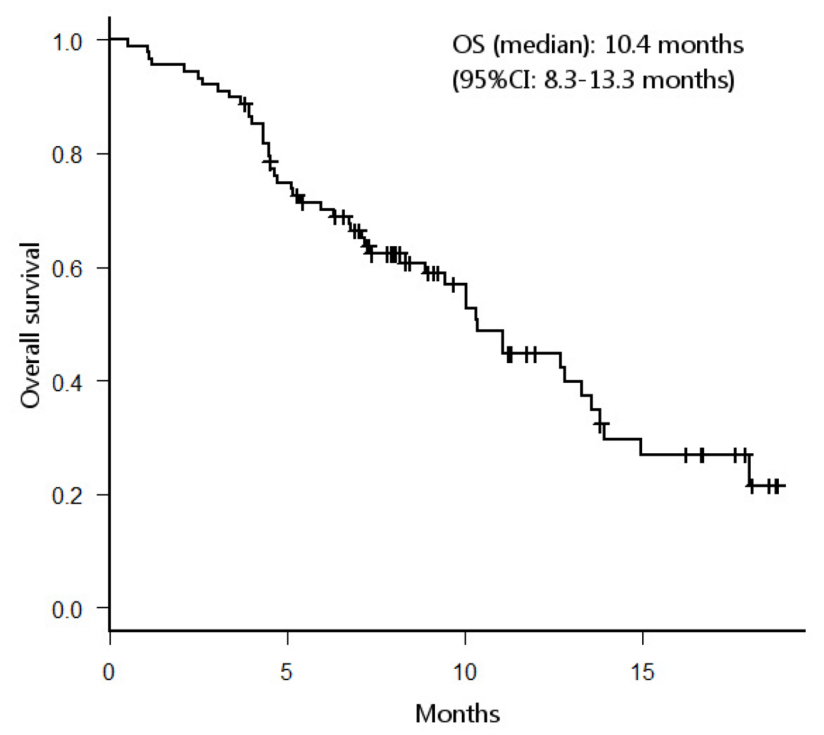

Figure 1: Probability of progression-free survival (PFS) (a) and overall survival (b) in all patients. 
Table 2: Best overall response in patients with measurable disease

\begin{tabular}{lc}
\hline Best overall response & $\mathbf{n = 4 0}$ \\
\hline Complete response & 0 \\
Partial response & $16(40 \%)$ \\
Stable disease & $9(23 \%)$ \\
Progressive disease & $13(33 \%)$ \\
Not evaluable or not assessed & $2(5 \%)$ \\
Objective response & $16(40 \%)$ \\
Disease control rate & $25(63 \%)$ \\
\hline
\end{tabular}

Table 3: Treatment-related adverse events

\begin{tabular}{|c|c|c|c|}
\hline & \multicolumn{3}{|c|}{$\mathrm{n}=\mathbf{8 9}$} \\
\hline & Grade 1-2 & Grade $\geq 3$ & Any Grade \\
\hline \multicolumn{4}{|c|}{ Non-hematological adverse events } \\
\hline Peripheral neuropathy & $38(43 \%)$ & $3(3 \%)$ & $41(46 \%)$ \\
\hline Fatigue & $27(30 \%)$ & $2(2 \%)$ & $29(33 \%)$ \\
\hline Nausea & $17(19 \%)$ & 0 & $17(19 \%)$ \\
\hline Anorexia & $15(17 \%)$ & 0 & $15(17 \%)$ \\
\hline Constipation & $9(10 \%)$ & $1(1 \%)$ & $10(12 \%)$ \\
\hline Diarrhea & $9(10 \%)$ & 0 & $9(10 \%)$ \\
\hline Liver abscess & 0 & $1(1 \%)$ & $1(1 \%)$ \\
\hline Aspiration pneumonia & 0 & $1(1 \%)$ & $1(1 \%)$ \\
\hline Febrile neutropenia & 0 & $1(1 \%)$ & $1(1 \%)$ \\
\hline \multicolumn{4}{|l|}{ Hematological adverse events } \\
\hline Neutropenia & $27(30 \%)$ & $35(39 \%)$ & $62(70 \%)$ \\
\hline Anemia & $28(31 \%)$ & 0 & $28(31 \%)$ \\
\hline Thrombocytopenia & $3(3 \%)$ & $1(1 \%)$ & $4(4 \%)$ \\
\hline Elevated liver enzyme & $2(2 \%)$ & 0 & $2(2 \%)$ \\
\hline \multicolumn{4}{|c|}{ Adverse events of special interest } \\
\hline Hypertension & $27(30 \%)$ & $6(7 \%)$ & $33(38 \%)$ \\
\hline Bleeding or hemorrhage & $26(29 \%)$ & 0 & $26(29 \%)$ \\
\hline Proteinuria & $16(18 \%)$ & 0 & $16(18 \%)$ \\
\hline Thromboembolic event & $1(1 \%)$ & $1(1 \%)$ & $2(2 \%)$ \\
\hline Gastrointestinal perforation & 0 & $1(1 \%)$ & $1(1 \%)$ \\
\hline Portal vein thrombosis & 0 & $1(1 \%)$ & $1(1 \%)$ \\
\hline Interstitial pneumonia & 0 & $1(1 \%)$ & $1(1 \%)$ \\
\hline
\end{tabular}

In their pharmacokinetic analyses of RAINBOW trial data, Tabernero et al. found that higher ramucirumab exposure, which might result in increased incidence of hypertension and other treatment-related toxicities, were associated with better efficacy [19]. A similar trend was observed in non-small cell lung cancer patients treated with ramucirumab + docetaxel in the phase 3 REVEL trial [20]. However, serum ramucirumab concentration was not associated with the incidence of hypertension in gastric cancer patients who received ramucirumab monotherapy 
in the REGARD trial or in colorectal cancer patients who received ramucirumab + FOLFIRI in the RAISE trial [19, 21]. Associations between hypertension and treatment efficacy have thus been reported mainly in patients treated with ramucirumab with taxanes, and the underlying mechanisms remain unknown. Drug-drug interactions between ramucirumab and paclitaxel or docetaxel were not observed in two separate phase II trials [22, 23]. In another study, analysis of ROSE/TRIO-012 trial data revealed that several single nucleotide polymorphisms (SNPs) related to VEGF pathways or drug metabolism/ transport were associated with the risk of hypertension

(a)

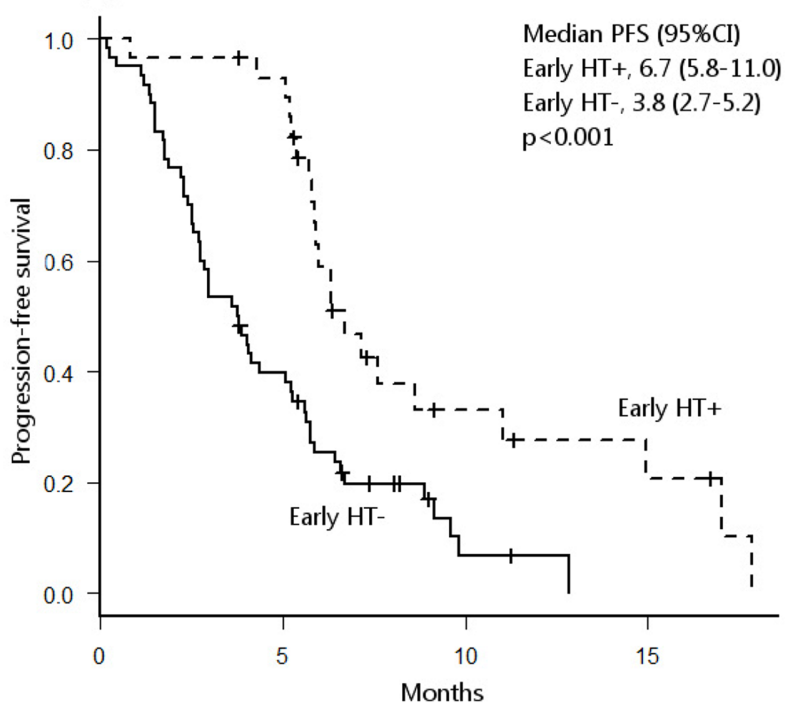

(c)

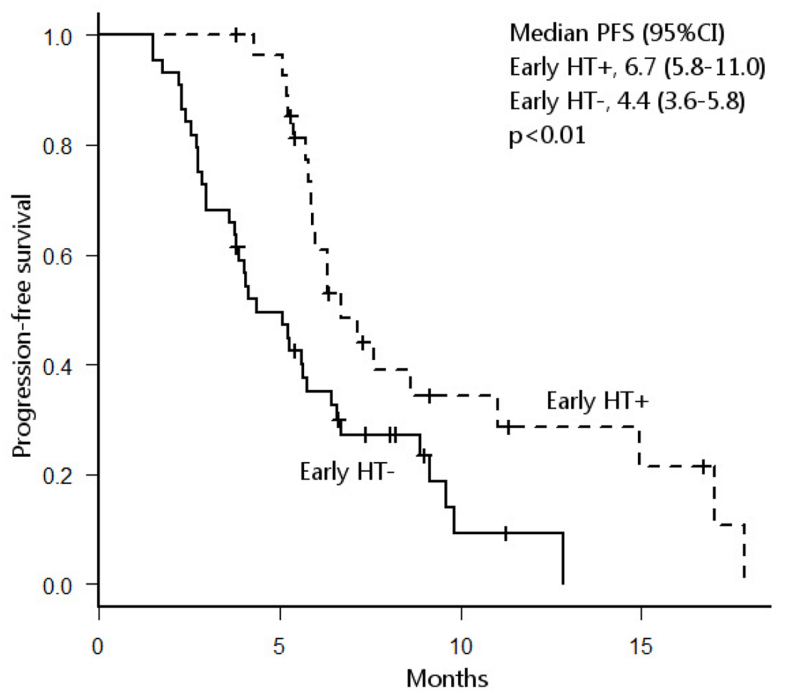

[24]. When considered together, these previous reports and our findings suggest that elevated ramucirumab exposure may result from genetic variations in VEGF signaling or drug metabolism/transport molecules, and that these exposures can result in both early hypertension and prolonged survival.

Ramucirumab-associated early hypertension might be a useful indicator of anti-tumor activity in advanced gastric cancer patients undergoing treatment with ramucirumab + paclitaxel. This is similar to previous findings demonstrating that cetuximab- or panitumumabinduced rashes serving as a predictive marker for longer

(b)

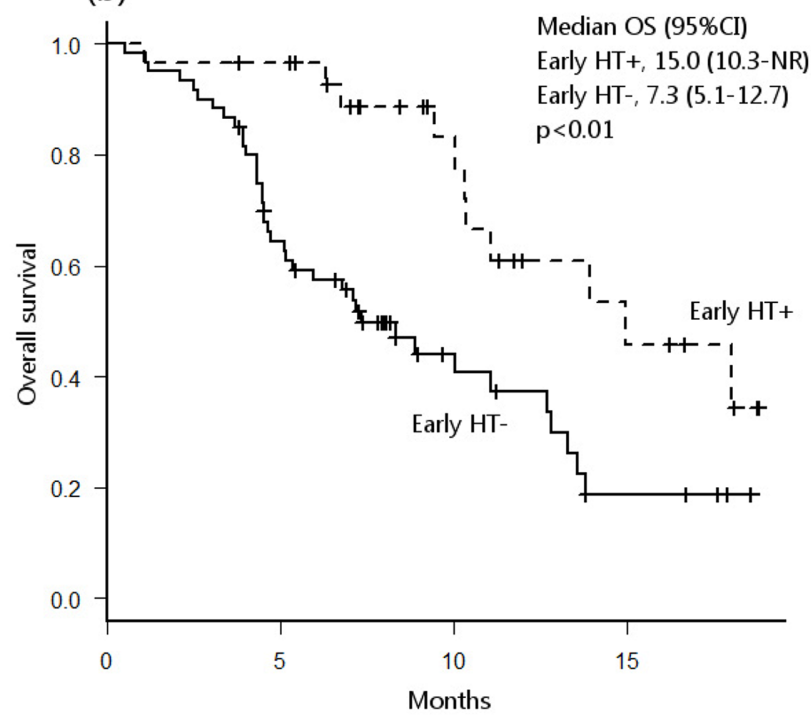

(d)

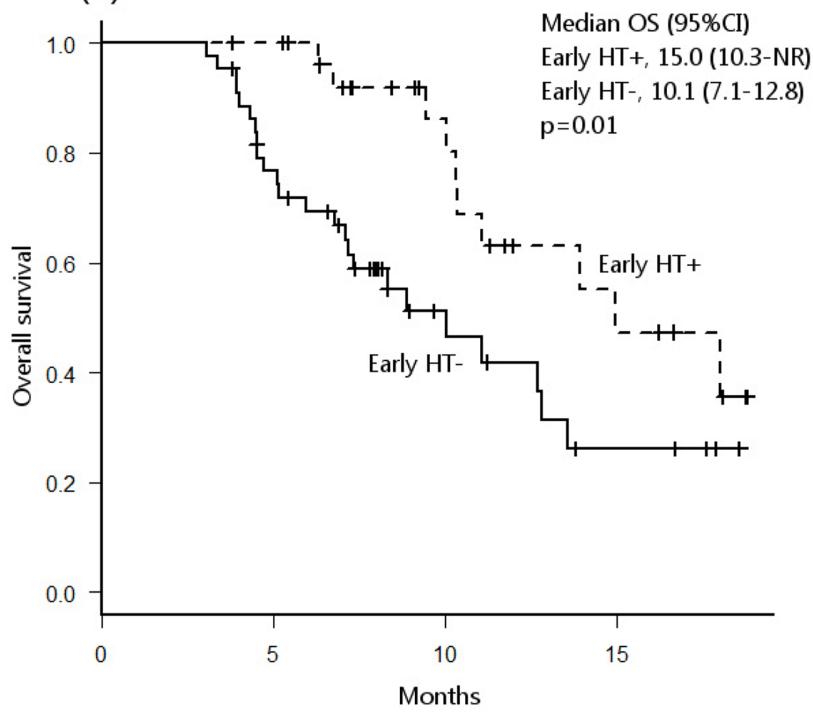

Figure 2: Probability of progression-free survival (PFS) (a) and overall survival (OS) (b) in all patients with and without early hypertension (HT). Probability of PFS (c) and OS (d) in all patients who received more than 2 ramucirumab treatment cycles. NR, not reached. 
Table 4: Multivariate analysis of PFS and OS in patients who received more than 2 treatment cycles

\begin{tabular}{lcccccccc}
\hline & \multicolumn{3}{c}{ Progression-free survival } & & \multicolumn{3}{c}{ Overall survival } \\
\cline { 2 - 3 } & HR & $\mathbf{9 5 \% C I}$ & p-value & & HR & $\mathbf{9 5 \% C I}$ & p-value \\
\hline Age $(\geq 65$ vs. $<65$ yrs) & 1.50 & $0.82-2.72$ & 0.18 & & 1.03 & $0.49-2.16$ & 0.94 \\
Sex (male vs. female) & 0.48 & $0.26-0.88$ & 0.02 & & 0.34 & $0.16-0.75$ & $<0.01$ \\
ECOG PS ( $\geq 2$ vs. 0-1) & 0.96 & $0.37-2.48$ & 0.93 & & 0.64 & $0.14-2.82$ & 0.56 \\
No. of prior regimens ( $\geq 2$ vs. 0-1) & 1.96 & $0.66-5.85$ & 0.23 & & 1.91 & $0.49-7.38$ & 0.35 \\
Presence of primary tumor & 1.70 & $0.91-3.14$ & 0.09 & & 2.28 & & $1.07-4.88$ & 0.03 \\
Number of metastatic sites ( $\geq 2$ vs. 0-1) & 0.88 & $0.46-1.67$ & 0.69 & & 1.12 & $0.51-2.44$ & 0.77 \\
Hypertension within 2 cycles & 0.39 & $0.21-0.73$ & $<0.01$ & & 0.45 & $0.21-0.96$ & 0.04 \\
\hline
\end{tabular}

OS in colorectal cancer patients [25-27]. Because adverse events like these are easy to observe, they can be evaluated at any time in any healthcare site at very little cost. Our present findings suggest that appropriate management of blood pressure can not only prevent treatment discontinuation, but also improve the efficacy of ramucirumab treatment.

Our study has several limitations. First, this was a retrospective analysis of a relatively small number of patients at a single institute. Because the patients were treated in clinical settings, the treatment procedures (e.g., timing of $\mathrm{CT}$ evaluations and dose modifications) were not highly standardized. A multicenter, protocol-based, prospective study in a larger patient cohort is therefore required. Second, we do not have any serum drug concentration or genetic polymorphism data, which were examined in previous reports, for the patients in this study. Third, these toxicities might only be surrogate markers for other serum biomarkers. Several authors have examined relative changes in circulating biomarker levels, including VEGF family members, during ramucirumab treatment [28]. However, the association between these biomarkers and hypertension has not been examined much. We are currently conducting an analysis of molecular biomarkers, including VEGF family members, to clarify the precise meaning of our findings.

In conclusion, ramucirumab-induced hypertension that arose within two treatment cycles was associated with longer PFS and OS in gastric cancer patients. This treatment-induced hypertension might be predictive of response to ramucirumab + paclitaxel treatment. Molecular markers and genetic variations should also be examined to support and expand on our findings.

\section{MATERIALS AND METHODS}

This retrospective analysis included patients with confirmed advanced gastric cancer or adenocarcinoma of the gastro-esophageal junction who were treated with ramucirumab + paclitaxel between June 2015 and October
2016 at our hospital's Department of Gastroenterology. All patients received $8 \mathrm{mg} / \mathrm{kg}$ ramucirumab intravenously on days 1 and 15 and $80 \mathrm{mg} / \mathrm{m}^{2}$ paclitaxel intravenously on days 1,8 , and 15 of a 28 -day cycle. Premedication with an $\mathrm{H} 1$ and $\mathrm{H} 2$ histamine antagonist plus dexamethasone was administered before each infusion. Intravenous granisetron (a 5-HT3 antagonist) was also administered for antiemetic prophylaxis on each day of paclitaxel infusion. Treatment continued until disease progression or unacceptable toxicity despite appropriate dose reduction occurred or until the patient refused further treatment.

Treatment response was evaluated every 6-8 weeks, or sooner in patients in whom disease progression was suspected, using CT scans and the Response Evaluation Criteria in Solid Tumors (RECIST) criteria (ver. 1.1). PFS was defined as the time between the initiation of treatment and disease progression or death by any cause. OS was defined as the time between the initiation of the treatment and the patient's last visit or death due to any cause. Toxicities were recorded and classified using the National Cancer Institute Common Terminology Criteria for Adverse Events (NCI-CTCAE) ver. 4.0.

Statistical analyses were performed in EZR (R ver. 2.13.0) [29]. PFS and OS were estimated using the Kaplan-Meier method and were compared using a logrank test. Survival results are expressed as median values with 95\%CIs. Prognostic factors were analyzed in both univariate and multivariate analyses. A Cox hazard regression model was used for the multivariate analysis of survival. Fisher's exact test was used to compare proportions. Statistical significance was defined as $p<0.05$.

Due to the retrospective nature of this study, the requirement for informed consent from the patients was waived by our hospital's institutional review board. This study was approved by the institutional review board of the Cancer Institute Hospital of JFCR (No. 2017-1006) and was conducted in accordance with the Helsinki Declaration of 1964 and later versions. 


\section{Abbreviations}

VEGF: vascular endothelial growth factor; ORR: objective response rate; PFS: progression-free survival; 95\%CI: 95\% confidence interval; OS: overall survival; HR: hazard ratio; QOL: quality of life; VEGFR: vascular endothelial growth factor receptor; yrs: years; ECOG: Eastern Cooperative Oncology; PS: performance status; HER2: human epidermal growth factor receptor-2; PR: partial response; SD: stable disease; PD: progressive disease; CTCAE: Common Terminology Criteria for Adverse Events; OR: odds ratio; eNOS: endothelial nitric oxide synthase; NO: nitric oxide; PI3K: phosphoinositide 3-kinase; SNPs: single nucleotide polymorphisms; CT: computed tomography; 5-HT3: 5-hydroxytryptamine receptor-3; RECIST: Response Evaluation Criteria in Solid Tumors; NCI-CTCAE: the National Cancer Institute Common Terminology Criteria for Adverse Events; HT: hypertension; NR: not reached.

\section{CONFLICTS OF INTEREST}

The authors declare that they have no conflicts of interest.

\section{FUNDING}

None.

\section{REFERENCES}

1. Japan NC. Projected Cancer Statistics. http:/ganjoho.jp/en/ public/statistics/short_pred.html (2016).

2. Koizumi W, Narahara H, Hara T, Takagane A, Akiya T, Takagi M, Miyashita K, Nishizaki T, Kobayashi O, Takiyama W, Toh Y, Nagaie T, Takagi S, et al. S-1 plus cisplatin versus S-1 alone for first-line treatment of advanced gastric cancer (SPIRITS trial): a phase III trial. Lancet Oncol. 2008; 9:215-21. https://doi.org/10.1016/ S1470-2045(08)70035-4.

3. Yamaguchi K, Sawaki A, Doi T, Satoh T, Yamada Y, Omuro Y, Nishina T, Boku N, Chin K, Hamamoto Y, Takiuchi H, Komatsu Y, Saji S, et al. Efficacy and safety of capecitabine plus cisplatin in Japanese patients with advanced or metastatic gastric cancer: subset analyses of the AVAGAST study and the ToGA study. Gastric Cancer. 2013; 16:17582. https://doi.org/10.1007/s10120-012-0167-0.

4. Yamada Y, Higuchi K, Nishikawa K, Gotoh M, Fuse N, Sugimoto N, Nishina T, Amagai K, Chin K, Niwa Y, Tsuji A, Imamura H, Tsuda M, et al. Phase III study comparing oxaliplatin plus S-1 with cisplatin plus S-1 in chemotherapynaïve patients with advanced gastric cancer. Ann Oncol. 2015; 26:141-48. https://doi.org/10.1093/annonc/mdu472.

5. Kim GM, Jeung HC, Rha SY, Kim HS, Jung I, Nam BH, Lee KH, Chung HC. A randomized phase II trial of
S-1-oxaliplatin versus capecitabine-oxaliplatin in advanced gastric cancer. Eur J Cancer. 2012; 48:518-26. https://doi. org/10.1016/j.ejca.2011.12.017.

6. Hironaka S, Ueda S, Yasui H, Nishina T, Tsuda M, Tsumura T, Sugimoto N, Shimodaira H, Tokunaga S, Moriwaki T, Esaki T, Nagase M, Fujitani K, et al. Randomized, openlabel, phase III study comparing irinotecan with paclitaxel in patients with advanced gastric cancer without severe peritoneal metastasis after failure of prior combination chemotherapy using fluoropyrimidine plus platinum: WJOG 4007 trial. J Clin Oncol. 2013; 31:4438-44. https:// doi.org/10.1200/JCO.2012.48.5805.

7. Spratlin JL, Cohen RB, Eadens M, Gore L, Camidge DR, Diab S, Leong S, O'Bryant C, Chow LQ, Serkova NJ, Meropol NJ, Lewis NL, Chiorean EG, et al. Phase I pharmacologic and biologic study of ramucirumab (IMC1121B), a fully human immunoglobulin G1 monoclonal antibody targeting the vascular endothelial growth factor receptor-2. J Clin Oncol. 2010; 28:780-87. https://doi. org/10.1200/JCO.2009.23.7537.

8. Wilke H, Muro K, Van Cutsem E, Oh SC, Bodoky G, Shimada Y, Hironaka S, Sugimoto N, Lipatov O, Kim TY, Cunningham D, Rougier P, Komatsu Y, et al, and RAINBOW Study Group. Ramucirumab plus paclitaxel versus placebo plus paclitaxel in patients with previously treated advanced gastric or gastro-oesophageal junction adenocarcinoma (RAINBOW): a double-blind, randomised phase 3 trial. Lancet Oncol. 2014; 15:1224-35. https://doi. org/10.1016/S1470-2045(14)70420-6.

9. Fuchs CS, Tomasek J, Yong CJ, Dumitru F, Passalacqua R, Goswami C, Safran H, Dos Santos LV, Aprile G, Ferry DR, Melichar B, Tehfe M, Topuzov E, et al, and REGARD Trial Investigators. Ramucirumab monotherapy for previously treated advanced gastric or gastro-oesophageal junction adenocarcinoma (REGARD): an international, randomised, multicentre, placebo-controlled, phase 3 trial. Lancet. 2014; 383:31-39. https://doi.org/10.1016/ S0140-6736(13)61719-5.

10. Zhu X, Wu S, Dahut WL, Parikh CR. Risks of proteinuria and hypertension with bevacizumab, an antibody against vascular endothelial growth factor: systematic review and meta-analysis. Am J Kidney Dis. 2007; 49:186-93. https:// doi.org/10.1053/j.ajkd.2006.11.039.

11. Scartozzi M, Galizia E, Chiorrini S, Giampieri R, Berardi R, Pierantoni C, Cascinu S. Arterial hypertension correlates with clinical outcome in colorectal cancer patients treated with first-line bevacizumab. Ann Oncol. 2009; 20:227-30. https://doi.org/10.1093/annonc/mdn637.

12. Rixe O, Billemont B, Izzedine H. Hypertension as a predictive factor of Sunitinib activity. Ann Oncol. 2007; 18:1117. https://doi.org/10.1093/annonc/mdm184.

13. Dahlberg SE, Sandler AB, Brahmer JR, Schiller JH, Johnson DH. Clinical course of advanced non-small-cell lung cancer patients experiencing hypertension during treatment with bevacizumab in combination with carboplatin and paclitaxel 
on ECOG 4599. J Clin Oncol. 2010; 28:949-54. https://doi. org/10.1200/JCO.2009.25.4482.

14. Mackey JR, Houé V, Thireau F, Lindsay MA, Fresco R. Reply to H.J. Lee et al. J Clin Oncol. 2015; 33:2712-13. https://doi.org/10.1200/JCO.2015.61.6748.

15. Facemire CS, Nixon AB, Griffiths R, Hurwitz H, Coffman TM. Vascular endothelial growth factor receptor 2 controls blood pressure by regulating nitric oxide synthase expression. Hypertension. 2009; 54:652-58. https://doi. org/10.1161/HYPERTENSIONAHA.109.129973.

16. Mourad JJ, des Guetz G, Debbabi H, Levy BI. Blood pressure rise following angiogenesis inhibition by bevacizumab. A crucial role for microcirculation. Ann Oncol. 2008; 19:927-34. https://doi.org/10.1093/annonc/ mdm550.

17. Mackey JR, Ramos-Vazquez M, Lipatov O, McCarthy N, Krasnozhon D, Semiglazov V, Manikhas A, Gelmon KA, Konecny GE, Webster M, Hegg R, Verma S, Gorbunova $\mathrm{V}$, et al. Primary results of ROSE/TRIO-12, a randomized placebo-controlled phase III trial evaluating the addition of ramucirumab to first-line docetaxel chemotherapy in metastatic breast cancer. J Clin Oncol. 2015; 33:141-48. https://doi.org/10.1200/JCO.2014.57.1513.

18. Garcia JA, Hudes GR, Choueiri TK, Stadler WM, Wood LS, Gurtler J, Bhatia S, Joshi A, Hozak RR, Xu Y, Schwartz JD, Thompson JA. A phase 2, single-arm study of ramucirumab in patients with metastatic renal cell carcinoma with disease progression on or intolerance to tyrosine kinase inhibitor therapy. Cancer. 2014; 120:1647-55. https://doi. org/10.1002/cncr.28634.

19. Tabernero J, Ohtsu A, Muro K, Van Cutsem E, Oh SC, Bodoky G, Shimada Y, Hironaka S, Ajani JA, Tomasek J, Safran H, Chandrawansa K, Hsu Y, et al. Exposure-response (E-R) relationship of ramucirumab (RAM) from two global, randomized, double-blind, phase 3 studies of patients (Pts) with advanced second-line gastric cancer. J Clin Oncol. 2015; 33:121.

20. Smit EF, Perol M, Reck M, Cappuzzo F, Bidoli P, Cohen RB, Gao L, Ernest CS, Lee P, Zimmermann A, Ferry D, Treat J, Melemed AS, Garon EB. Exposure-response relationship for ramucirumab (RAM) from the randomized, double-blind, phase III REVEL trial (docetaxel [DOC] vs DOC plus RAM) in second-line treatment of metastatic non-small cell lung cancer (NSCLC). J Clin Oncol. 2015; 33:8053.

21. Lonardi S, Cohn AL, Yoshino T, Obermannova R, Bodoky G, Prausová J, Garcia-Carbonero R, Ciuleanu T, GarciaAlfonso P, Portnoy DC, Van Cutsem E, Yamazaki K, Clingan PR, et al. Exposure-response (E-R) relationship of ramucirumab (RAM) from a global, randomized, double-blind, Phase 3 study of patients (Pts) with advanced 2nd line colorectal cancer. Ann Oncol. 2016; 27:iv40. https://doi.org/10.1093/annonc/mdw335.04.

22. Chow LQ, Smith DC, Tan AR, Denlinger CS, Wang D, Shepard DR, Chaudhary A, Lin Y, Gao L. Lack of pharmacokinetic drug-drug interaction between ramucirumab and paclitaxel in a phase II study of patients with advanced malignant solid tumors. Cancer Chemother Pharmacol. 2016; 78:433-41. https://doi.org/10.1007/s00280-016-3098-3.

23. Stein MN, Chow LQM, Smith DC, Shepard DR, Wang D, Powderly J, Chaudhary A, Lin Y, Gao L. Phase II study evaluating the effect of concomitant ramucirumab on the pharmacokinetics of docetaxel in patients with advanced solid tumors. Clin Pharmacol Biopharm. 2016; 5:161. https://doi.org/10.4172/2167-065X.1000161.

24. Mackey JR, Lipatov ON, Martin M, Webster M, Hegg R, Verma S, Vazquez MR, Fresco R, Thireau F, Houé V, Press MF, Narasimhan A, Damaraju S. Genetics of ramucirumabassociated hypertension in the ROSE/TRIO-012 breast cancer trial. J Clin Oncol. 2015; 33:547.

25. Cunningham D, Humblet Y, Siena S, Khayat D, Bleiberg H, Santoro A, Bets D, Mueser M, Harstrick A, Verslype C, Chau I, Van Cutsem E. Cetuximab monotherapy and cetuximab plus irinotecan in irinotecan-refractory metastatic colorectal cancer. N Engl J Med. 2004; 351:337-45. https://doi. org/10.1056/NEJMoa033025.

26. Saltz LB, Meropol NJ, Loehrer PJ Sr, Needle MN, Kopit J, Mayer RJ. Phase II trial of cetuximab in patients with refractory colorectal cancer that expresses the epidermal growth factor receptor. J Clin Oncol. 2004; 22:1201-08. https://doi.org/10.1200/JCO.2004.10.182.

27. Van Cutsem E, Peeters M, Siena S, Humblet Y, Hendlisz A, Neyns B, Canon JL, Van Laethem JL, Maurel J, Richardson G, Wolf M, Amado RG. Open-label phase III trial of panitumumab plus best supportive care compared with best supportive care alone in patients with chemotherapyrefractory metastatic colorectal cancer. J Clin Oncol. 2007; 25:1658-64. https://doi.org/10.1200/JCO.2006.08.1620.

28. Fuchs CS, Tabernero J, Tomášek J, Chau I, Melichar B, Safran H, Tehfe MA, Filip D, Topuzov E, Schlittler L, Udrea AA, Campbell W, Brincat S, et al. Biomarker analyses in REGARD gastric/GEJ carcinoma patients treated with VEGFR2-targeted antibody ramucirumab. Br J Cancer. 2016; 115:974-82. https://doi.org/10.1038/ bjc.2016.293.

29. Kanda Y. Investigation of the freely available easy-touse software 'EZR' for medical statistics. Bone Marrow Transplant. 2013; 48:452-58. https://doi.org/10.1038/ bmt.2012.244. 